\title{
EDITORIAL
}

\section{Winter Issue 2015}

DOI:http://dx.doi.org/10.5770/cgj.18.223

Hi! The editorial board of the Canadian Geriatrics Journal is delighted to present our winter issue containing a wide variety of original research. Xu et al. ${ }^{(1)}$ examines the ability of a pre-clerkship observership program to improve positive attitudes towards the practice of geriatric medicine. Another article examines the effectiveness of the DEAR (Delirium Elderly at Risk) tool at identifying hip fracture patients at risk for delirium. ${ }^{(2)}$ Forbes et al. ${ }^{(3)}$ presents a meta-analysis of the effect of various supplements on cognition.

As well, we are excited to showcase geriatric research occurring nationally by providing the abstracts presented at both the Canadian Consensus Conference ${ }^{4,5}$ on Dementia and the Canadian Association of Geriatric Psychiatry ${ }^{5}$ meetings this year.
See you in 2016 !

Dr. Ken Madden, Editor-in-Chief Dr. Mark Rapoport, Associate Editor Dr. Coleen Maxwell, Associate Editor

\section{REFERENCES}

1. You P, Leung, M, Xu VY, et al. Pre-clerkship observerships to increase early exposure to geriatric medicine. CGJ. 2015; 18(4):225-230.

2. Freter S, Dunbar M, Koller K, et al. Risk of pre- and post-operative delirium and the delirium elderly at risk (DEAR) tool in hip fracture patients. CGJ. 2015;18(4):212-216.

3. Forbes SC, Holroyd-Leduc JM, Poulin MJ, et al. Effect of nutrients, dietary supplements and vitamins on cognition: a systematic review and meta-analysis of randomized controlled trials. CGJ. 2015;18(4):231-245.

4. Oral Abstract Presentations at the 8th Canadian Conference on Dementia (CCD) Ottawa, October 2015. CGJ. 2015;18(4): 246-249.

5. Poster Presentations at the 8th Canadian Conference on Dementia (CCD) Ottawa, October 2015. CGJ. 2015;18(4):250-300. 